\title{
Imagen digital en Anatomía Patológica: desde el diágnóstico a la docencia y la investigación
}

\author{
Luis Alfaro Ferreres ${ }^{\text {a b c }}$, M $^{\mathrm{a}}$ José Roca Estellés $^{\mathrm{b}}$ y Carlos Pascual Roca \\ ${ }^{\mathrm{a}}$ Universidad CEU-Cardenal Herrera. Castellón, ${ }^{\mathrm{b}}$ Hospital 9 de Octubre. Valencia y ${ }^{\mathrm{c}}$ FISABIO \\ Oftalmología Médica. Valencia
}

\begin{abstract}
Pathology is the part of medicine performing diagnosis of diseases from the study of samples of patients' injuries. The basis of the diagnosis is the recognition and interpretation of the morphological alterations that diseases induce in the tissues and in the cells of the organism. There is an initial part, with the macroscopic study of the excised samples: biopsies and surgical specimens and a second with the microscopic analysis of the lesions. This process can now be done from the study of the digitized images of macroscopic and microscopic lesions. Pathology laboratories with a digital organization generate a huge amount of images with great value in teaching and research. To transfer these images from a hospital environment we have developed a web-based query system from hospital databases that are exported to MySQL and available from an Apache web server (XAMPP) where query forms are generated, through which students and researchers access all images of different pathologies. The system allows continuous updating and the potential integration of images from different sources
\end{abstract}

Keywords: digital image, pathological anatomy, image biobank, portability.

\section{Resumen}

La Anatomía Patológica se encarga del diagnóstico de las enfermedades a partir del estudio de muestras de la lesiones de los pacientes. La base del diagnóstico es el reconocimiento y la interpretación de las alteraciones morfológicas que las enfermedades inducen en los tejidos y en las células del organismo. Hay una parte inicial, con el estudio macroscópico de las muestras extirpadas: biopsias y piezas quirúrgicas y una segunda con el análisis microscópico de las lesiones. Este proceso en la actualidad se puede realizar a partir del estudio de las imágenes digitalizadas de las lesiones macroscópicas y microscópicas. Los servicios hospitalarios de Anatomía Patológica con una organización digital generan una enorme cantidad de imágenes con gran valor en la docencia y en la investigación. Para transferir estas imágenes desde entorno hospitalario hemos generado una un sistema de consulta en formato web a partir de las bases de datos hospitalarias que son exportadas a MySQL y accesibles desde un servidor web Apache (XAMPP) donde se generan los formularios de consulta a través de los cuales los 
estudiantes e investigadores acceden a la imágenes de las diferentes patologías. El sistema permite la actualización continua y la incorporación potencial de imágenes de diferente procedencia.

Palabras clave: imagen digital, anatomía patológica, bancos de imágenes, portabilidad.

\section{Introducción}

Los servicios hospitalarios de Anatomía Patológica están inmersos en un proceso progresivo de digitalización (Salas, 2009) que afecta diferentes ámbitos como la trazabilidad de las muestras, el diágnótico remoto (Alfaro, 2008), el control de calidad (Wei, 2014) y la sustitución de los microscopios por ordenadores que proyectan imágenes escaneadas a máximo aumento de las preparaciones microscópicas. El estudio macroscópico de las biopsias y piezas quirúrgicas está evolucionando, desde las clásicas descripciones narrativas en textos adjuntos a los informes, hacia la documentación fotográfica completa de todos los especímenes. Esta organización digital genera bancos de imágenes, que tienen un gran valor docente $\mathrm{y}$ un potencial aprovechamiento en investigación (ESR, 2015).

Por otro lado, la docencia universitaria en Anatomía Patológica ha adoptado sistemas digitales incluso con anterioridad a los hospitales (Poblet, 2013). La organización de seminarios y prácticas se ve agilizada cuando las salas de microscopios en las universidades se sustituyen por salas de ordenadores. Los estudiantes se manejan con facilidad en el uso de imágenes digitales, mientras que el aprendizaje del uso de los microscopio requiere un tiempo muy superior. Las preparaciones microscópicas tradicionales en portaobjetos de cristal tienen riesgo de rotura, pierden con el tiempo parcialmente la intensidad de tinción y requieren un elevado número de cortes en función del número de estudiantes y de microscopios. La imágenes digitales solucionan estos problemas y facilitan la interacción con el profesor.

Para los investigadores el acceso a patologías concretas, la identificación de procesos degenerativos, infecciosos o neoplásicos se facilita cuando existen bancos de imágenes digitales (Martínez, 2017) que permiten una clasificación exacta de las lesiones. El empleo de tejidos para técnicas moleculares de detección de mutaciones o secuenciación, requiere una selección precisa del tipo de lesión e incluso identificación exacta del área afecta, que las imágenes digitales aportan con detalle. Incluso en el propio proceso asistencial de diagnóstico primario, el acceso a imágenes de lesiones infrecuentes agiliza y facilita dicho diagnóstico.

En los últimos 10 años los servicios de Anatomía Patológica de los hospitales Vithas-Nisa 9 de Octubre y Virgen del Consuelo de Valencia y Rey don Jaime de Castellón han generado 
en el curso de su actividad asistencial un banco de imágenes digitales macro y microscópicas superior a las 500.000 .

\section{Objetivos}

El aprovechamiento en docencia e investigación de este banco de imágenes hospitalarias se planteó con las siguientes premisas:

- El sistema debía desarrollarse en un entorno web para la máxima facilidad de acceso.

- La imágenes deben estar anonimizadas sin información de filiación de los pacientes.

- Las imágenes deben estar relacionadas con la información clínica de las bases de datos hospitalarias con indicación del diagnóstico anatomopatológico, topografía de las lesiones y datos de edad y sexo de los pacientes.

- El sistema debe ser capaz de importar imágenes de diferentes hospitales con una actualización continua

- $\quad$ El sistema debe ser preferiblemente portable para su traslado e incorporación de imágenes externas

- Las consultas a las bases de datos deben hacerse a través de un formulario que incorpora los datos tabulados en las bases de datos

- La respuestas a las búsquedas del formulario deben aportar las imágenes que cumplan los criterios solicitados y presentarse en forma de iconos de pequeño tamaños enlazados con las imágenes a alta resolución.

\section{Desarrollo de la Innovación}

El sistema de información de Anatomía Patológica de nuestros hospitales cuenta con dos bases de datos. El sistema de información hospitalario (HIS) y el sistema de información propio del servicio. La primera de ellas por su propia naturaleza global no es adecuada para ser la fuente de conexión al banco de imágenes. La base de datos del servicio de Anatomía Patológica tiene la ventajas de incorporar todos los diagnósticos anatomopatológicos que lógicamente se generan en el propio servicio. Integra una numeración propia que comparte con el número de identificación de las imágenes. Está diseñada en tablas Access por lo que su manejo no requiere elevados conocimientos informáticos. A partir de esta base de datos Access se obtenían tablas html a las que se incorporaba un sencillo sistema de búsquedas basado en javascript:

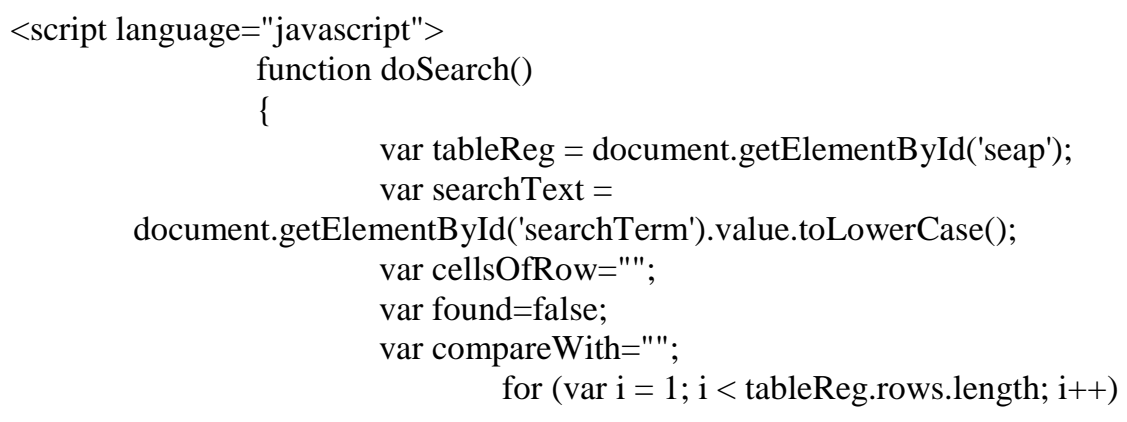


tableReg.rows[i].getElementsByTagName('td');

$$
\text { cellsOfRow }
$$

$$
\text { found = false; }
$$

for (var $\mathrm{j}=0$; $\mathrm{j}<$ cellsOfRow.length \&\& !found; $\mathrm{j++}$ )

\{

compareWith = cellsOfRow[j].innerHTML.toLowerCase();

if ( searchText.length $==0 \|($ compareWith.indexOf(searchText) $>-1)$ )

found = true;

\}

\}

$$
\text { found = true; }
$$

if(found)

\{

tableReg.rows[i].style.display = ";

\} else \{

tableReg.rows[i].style.display = 'none'; \}

\}

\}

$</$ script $>$

La tabla incorpora un pequeño cuadro de búsqueda con esta definición en HTML:

$<$ form $>$ $</$ form $>$

Buscar <input id="searchTerm" type="text" onkeyup="doSearch()" />

En un entorno médico, con bajo nivel de conocimiento en tecnologías de información, la sencillez del código de búsqueda, aunque no sea creado por los propios patólogos, es aprovechable de una manera directa sin necesidad de depender de personal especialidado.

El crecimiento del banco de imágenes limitó esta funcionalidad a subgrupos del total de imágenes con características determinadas. Para el manejo simultáneo de todas las imágenes se hizo necesario contar con una base de datos tipo MySQL (Roca, 2017). La conversión de las tablas de Access a MySQL se hizo con el software Access to MySQL de Bullzip. Durante el procedimiento se seleccionaban los campos de interés, excluyéndose el nombre de los pacientes.

Con la idea de conseguir un sistema completamente portable se utilizo un disco duro externo de 2,5" con una capacidad de 4 TB que permite almacenar la totalidad de las 500.000 imágenes y los thumbnails de cada una de ellas asi compo el servidor Apache en una versión portable (XAMPP). Los thumbnails de las imágenes se crearon con el programa XnView y con un tamaño de 250x150 pixeles (Fig. 1).

(cc)) EY-NC-ND 2018, Universitat Politècnica de València 


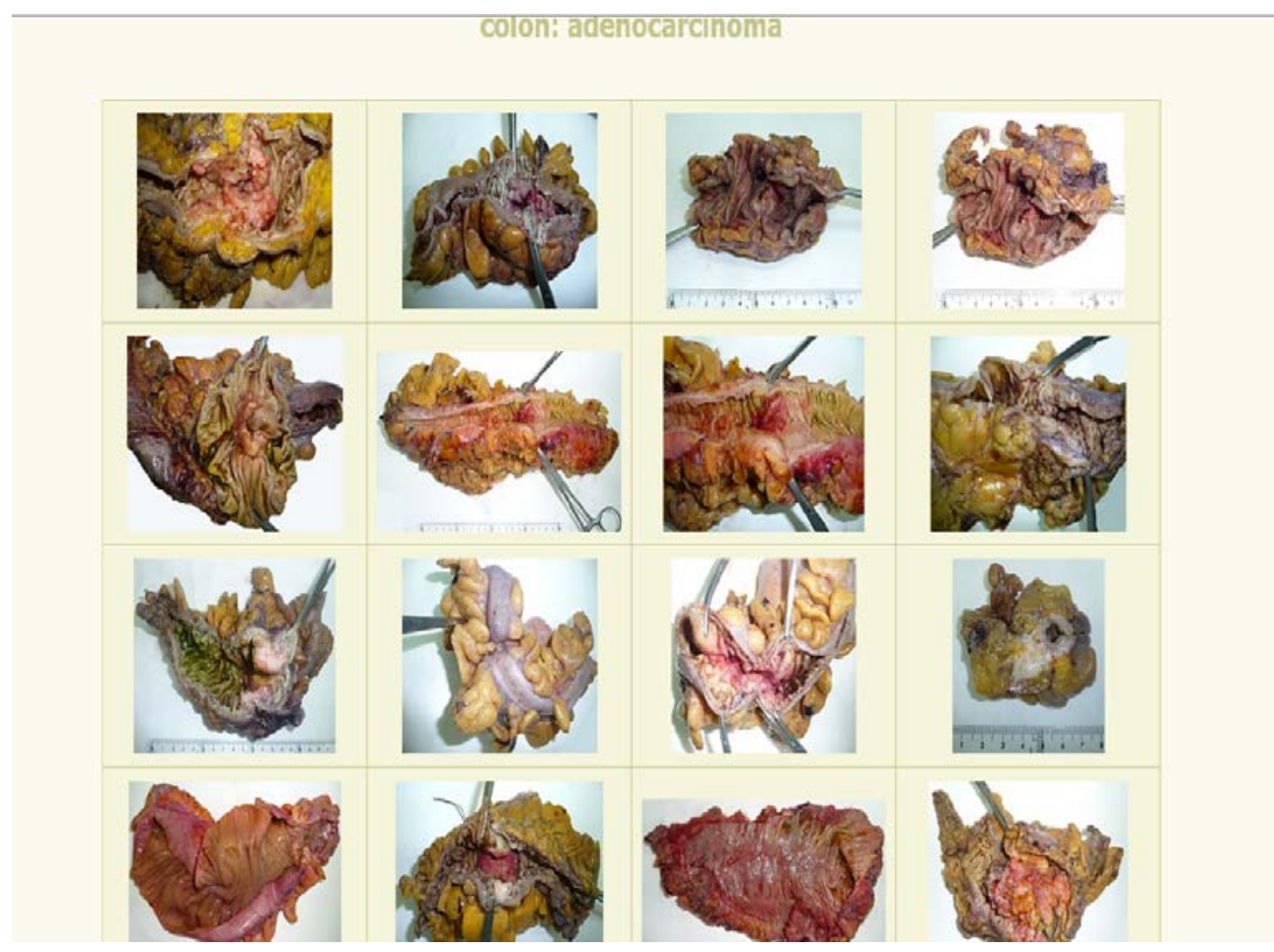

Fig. 1.- Ejemplo de presentación de imágenes macroscópicas de adenocarcinoma de colon.

El formulario de consulta a la bases de datos fue generado por uno de nosotros (C.P.R.) utilizando php como lenguaje de programación (Fig. 2). Para ello se tuvo en cuenta la ubicación de la imágenes en carpetas distribuidas por años y en subcarpetas que almacenan cada una un millar de casos. Por convención las imágenes macroscópicas se numeran con dos dígitos correspondiste al año seguido de un guión y el número del caso. Cuando hay más de una imagen por caso se añaden secuencialmente letras de manera alfabética. Las imágenes microscópicas se numeran de la misma manera pero anteponiendo el número del caso y la letra de número de orden, seguidas de un guión y los dos dígitos del año. Las imágnes de técnicas especiales de histoquimia, inmunohistoquímica, fluorescencia, etc. conservan el número del caso, al que se añade un sufijo que indica el tipo de técnica que expresan 


\section{Imágenes Anatomopatológicas}

Formulario de consulta

Conected to database

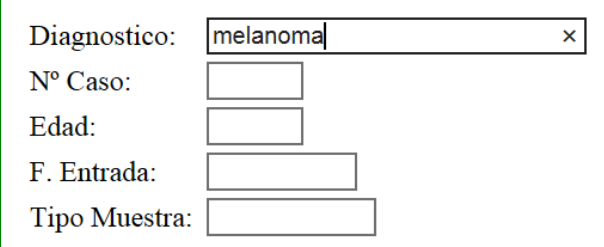

Tipo Muestra:

Fig. 2.- Formulario web de consulta al banco de imágnes.

\section{Resultados}

La presentación de resultados a partir del formulario de consulta muestra la colección de imágenes que cumplen los criterios de búsqueda en una pagina web con los thumbnails de cada caso, el diagnóstico completo de la lesión, el hospital de origen y el tipo de lesión (Fig. 3). Cuando el número de casos/imágenes es muy elevado, se generan automáticamente diversas páginas web ordenadas, conteniendo una distribución parcial de las imágenes en cada una de ellas hasta completar la totalidad. Cada thumbnail presentado está enlazado y muestra al pulsar sobre él la imagen original a alta resolución. 


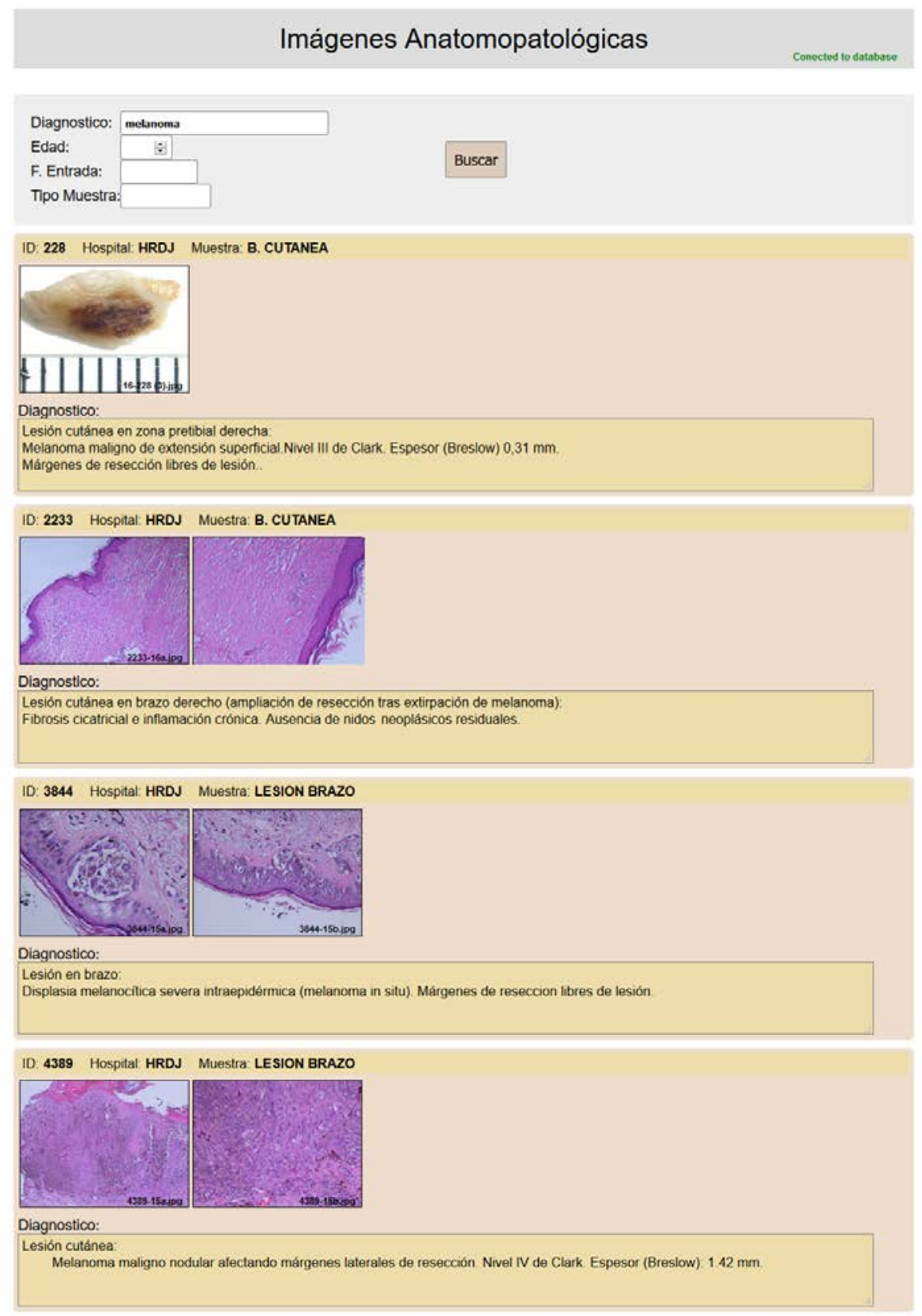

Fig. 3. Resultados de un ejemplo de busqueda de imágenes de melanoma cutáneo.

\section{Conclusiones}

El sistema descrito de gestión de imágenes permite aprovechar el enorme valor de nuestros archivos gráficos.

(c) ) EY-NC-ND 2018, Universitat Politècnica de València 
En la práctica diaria para un patólogo la revisión de las imágenes de casos previos es más informativa que la revisión del texto del informe ya que muestra los datos morfológicos que sustentan el diagnóstico, en lugar de la información orientada a los clínicos donde priman los criterios de categorización con información pronóstica y orientación terapéutica.

El aprovechamiento docente tanto para técnicos (macroscopía, citología...), (Gallardo, 2017) como para estudiantes pregrado justifica por sí solo la creación de estas colecciones. El gran número de casos disponibles abarca prácticamente la totalidad de las patologías, mostrando de cada categoría diagnóstica el espectro de variación morfológica posible. Los estudiantes tienen posibilidad de familiarizarse con las diferentes patologías accediendo a un gran número de lesiones de todas las ramas de la patología.

Nuestra experiencia aplicada progresivamente en los 6 últimos años en Anatomía Patológica en el grado de Medicina en la Universidad CEU Cardenal Herrera de Castellón, nos confirma la excelente adaptación de los estudiantes, el incremento de número de casos que pueden ser explicados en los seminarios y las prácticas, en relación con la metodología clásica de aulas con microscopios y proyectores, y el gran valor adicional para los estudiantes que representa el acceso a las imágenes desde cualquier ubicación y en cualquier horario.

El estudio retrospectivo de casos en investigación permite la revisión de un elevado número de casos en un tiempo muy reducido. La aplicación de nuevas tecnologías permite seleccionar con precisión los casos concretos que cumplen los criterios diseñados para cada investigación y seleccionar subcategorias con rasgos que van más allá de los que tienen interés clínico para ser mencionados en los informes de diagnóstico anatomopatológico. La selección retrospectiva de bloques de tejido en los estudios de biología molecular para extraer ADN/ARN permite seleccionar exactamente las neoplasias de más interés conociendo con más precisión la de carga tumoral en relación al estroma tisular, el componente inflamatorio o el grado de necrosis, que son factores que pueden alterar el resultado de las técnicas moleculares, si no se escogen las zonas concretas representativas de la celularidad tumoral.

El diseño portable y el entorno web hace posible exportar el sistema a cualquier banco de imágenes en un tiempo muy reducido. Basta con reconfigurar la distribución de las imágenes, hacer compatible la numeración de las mismas con los criterios de búsqueda programados y exportar la bases de datos original a MySQL.

\section{Referencias}

ALFARO FERRERES, L. y ROCA ESTELLÉS, M.J. (2008). "Portable Telepathology: Methods and Tools". Diagnostic Pathology, Vol. 3 (Suppl. 1), p. 19-21.

European Society of Radiology (ESR). (2015). “ESR Position Paper on Imaging Biobanks. Insights”. Imaging. 2015. Vol. 6, issue 4, p. 403-10.

$<$ https://www.ncbi.nlm.nih.gov/pmc/articles/PMC4519817/> [Consulta: 20 de marzo de 2018].

GALlARDO SANZ, B., ALFARO FERRERES, L., DOMÍNGEZ RECOBERT, M. y HUART PERIS, M.C., (2017) "Beneficios de la fotografía microscópica en la mejora del diagnóstico en la

(cc) EY-NC-ND 2018, Universitat Politècnica de València

Congreso IN-RED (2018) 
citología ginecológica” en $28^{\circ}$ Congreso Nacional de la Sociedad Española de Anatomía Patológica. Valencia.

MARTÍNEZ, J. (2017). "Biobancos con fines de investigación biomédica y Bancos de imágenes“ en VI Curso de Patología Digital. Valencia FISABIO Oftalmología Médica $<$ http://digipat.org> [Consulta: 20 de marzo de 2018].

POBLET MARTÍNEZ, E., MORO RODRÍGUEZ, E., ALFARO FERRERES, L. (2013). “Patología digital y docencia” en: Libro Blanco de la Anatomía Patológica en España (C) SEAP, págs. 105-109.

ROCA ESTELLÉS, M.J., ALFARO FERRERES, L. y PASCUAL ROCA, C. (2017).

"Bancos de imágenes digitales en anatomía patológica. Metodología y aplicaciones" en $28^{\circ}$ Congreso Nacional de la Sociedad Española de Anatomía Patológica. Valencia.

SALAS VALIEN, J.S., GARCÍA ROJO, M. y ALFARO FERRERES, L. (2009).

“Tecnología de la Información en los Servicios de Anatomía Patológica” en: Libro Blanco de la Anatomía Patológica en España @ SEAP; págs: 185-194.

WEI B.R. y SIMPSON R.M. (2014). "Digital pathology and image analysis augment biospecimen annotation and biobank quality assurance harmonization”. Clin Biochem. vol, 47 issue 4-5, p. 274-9 https://www.ncbi.nlm.nih.gov/pmc/articles/PMC4975042/ [Consulta: 20 de marzo de 2018]. 